\title{
Antihypertensive Activity of Aqueous Extract of Adhatoda Vasica in Hypertensive Rats.
}

\author{
${ }^{*}$ Satkar Prasad ${ }^{1}$, Sailesh Kumar Ghatuary ${ }^{2}$, Anil Sarathe ${ }^{3}$, Gaurav Dubey ${ }^{4}$, \\ Kalpana Prajapati ${ }^{5}$, Reena Shinde ${ }^{6}$. \\ ${ }^{I}$ (Dept. of Pharmachemistry, RKDF School of Pharmaceutical Science. Bhopal, India) \\ ${ }^{2}$ (Dept. of Pharmaceutics, RKDF School of Pharmaceutical Science. Bhopal, India) \\ ${ }^{3}$ (Dept. of Pharmacology, RKDF School of Pharmaceutical Science. Bhopal, India) \\ Corresponding Author: Satkar Prasad ${ }^{l}$
}

\begin{abstract}
The present study involved the evaluation of effectiveness of aqueous extract of Adhatoda Vasica on blood pressure, Systolic blood pressure, diastolic blood pressure and mean arterial blood pressure in the hypertensive rats. The result of present study was shown that the pretreatment with aqueous extract of adhatoda vasica (100, $200 \& 400 \mathrm{mg} / \mathrm{Kg}$ p.o) for six week and on the day of experiment after administration of aqueous extract of adhatoda Vasica $(10,20 \& 40 \mathrm{mg} / \mathrm{kg}$ i.v.) produced significant reduction in $B P, S B P, D B P$ and MABP at different time interval in dose dependant manner. The positive control, Captopril at the dose of $1 \mathrm{mg} / \mathrm{kg}$ was shown significant decrease in the elevated blood pressure in Goldblatt model. It reveals that antihypertensive effect observed for aqueous extract of adhatoda vasica in present study due to decrease rennin release and angiotensin II levels: AT1 and AT2 receptors antagonism: inhibition of aldosterone secreation: increased prostaglandin synthesis or inhibition of ACE that is involved in angiotensin II from angiotensin I.
\end{abstract}

Date of Submission: $\mathrm{xx}-\mathrm{xx}-\mathrm{xxxx}$

Date of acceptance: $\mathrm{xx}-\mathrm{xx}-\mathrm{xxxx}$

\section{Introduction}

Cardiovascular disease (CVD) is leading and major contributor to the global disease burden. Importantly, (CVD) is eminently preventable to large extent. In order to achieve significant reduction in the avoidable (CVD) burden, a combination of population-based and high risk strategy is necessary. These strategies should target life-style related risk factor such as un healthy diet, physical inactivity and tobacco misuse as well as the intermediate manifestation of these lifestyle; e.g. hypertension glucose intolerance, and hyperlipidemia. In addition, the strategies, aimed at improving management of those already affected by CVD should be an integral component of a comphrensive approach, for the prevention and control of CVD (1). Hypertension (HT) has been evidently, the most important contributing factor to cardiovascular disease, the leading causes of morbidity and untimely death. Sustained hypertension damage heart,kidney, blood vessel and brain which lead to ischemic heart disease, congestive heart failure, renal failure and stroke. Hypertension, therefore, is one of the most serious concerns of modern medical practice (2).

Many synthesis drugs have been developed for the treatment of hypertension because of the severity and prevalence of the disease. Herbal medicine have been regaining importance because of their ease of availability less side effect and cost effective (3). Adhatoda vasica belonging to family Acanthaceae. Leaves are 9-24 cm in length, opposite, lanceolate, Acuminate, minutely puberulous when young, glabrous hen mature, entire dark green, paler beneath, base tapering (4). Adhatoda vasica nees is an important medicinal plant widely employed for a variety of ailment in ancient Indian medicine. Recent investigation has reaffirmed the versatile activities of vasicine, the major alkaloid in the plant, as a highly potent expectorant, oxytocic and an abotificient agent (5). The literature survey reveals that the plant Adhatoda vasica having Anticestodal activity (6), Antiulcer activity (7), Antitussive activity (8), Antituberculosis activity (9), Hepatoprotective activity (10), Modulatory influence activity (11), Anti-inflammatory activity (12), Anthelmintic activity (13), inhibitory effect (14) and antidiabetic activity (15).

\section{Material And Method}

\subsection{Materials}

\subsubsection{Collection and Identification of plant material}

The leaves of Adhatoda Vasica was collected from Bhor (Dist - Pune, Maharastra, India) in the month of October 2012 and were authenticated by the Agharkar research institute, Pune.

\subsubsection{Extraction of Leaves}


The leaves were dried under shade and powdered by using grinder mixture. For the prepration of aqueous extracts powdered material $(1000 \mathrm{gm})$ was extracted with distilled water at $100^{\circ} \mathrm{C}$ for $8-10$ hour by using soxhlet apparatus. Extraction was done under reflux with an appropriate volume of distilled water. Extract was dried at $60^{\circ} \mathrm{C}$ on water bath, yielding a reddish coloured dry mass of $28 \mathrm{gm}(2.80 \% \mathrm{w} / \mathrm{w})$. The extract was then preserved in the desiccators (16).

\subsubsection{Preparation of drug solution}

Accurately weighed quantity of extract was dissolved in the distilled water to prepare the appropriate stock solution of the extract. The doses administered orally by selecting the appropriate concentration of the stock solution. Aciten dispersible tablet (Captopril 25mg) was dispered in distilled water. The doses were administered by selecting the appropriate concentration $(100 \mathrm{ml} / \mathrm{kg})$ of the stock solution

\subsubsection{Animal}

Male wistar albino rats of weighing between (200-250 g) were used. They were maintained at $25^{\circ} \mathrm{c} \pm$ $2^{\circ} \mathrm{c}$ and relative humidity of 45 to $55 \%$ and under standard environmental condition (12 hours light/12 hours dark cycle). The animal had free access to food (pranav Agro Industries Ltd Sangli india) and water. Animal were obtained from Yash farm, Pune, Maharastra, India and national toxicological centre, Pune, Maharastra, India. All the experiment Protocol was approved by institutional Animal Ethics Committee (IAEC)

\subsubsection{Daily acclimatization of animal}

The animals were shifted from animal house to the laboratory one hour prior to the experiment. The respective apparatus were cleaned with hydrogen peroxide or damp cloth wherever necessary to avoid possible bias due to odour trials left by the previous animal.

\subsubsection{Storage condition}

All the solutions were prepared freshly and use on the day of dosing. The solution were stored, if required, in airtight amber colored vials in the refrigerator.

\subsection{Methods}

\subsubsection{Acute toxicity studies}

In order to decide the dose, toxicity study was carried out as per OECD guidelines No. 423; CPCSEA for acute oral toxicity.

Female mice were randomly selected and marked for individual identification. Animal were fasted $24 \mathrm{~h}$ prior to dosing of aqueous extract of A. Vasica were administered in a single dose orally. Toxicity study was carried out using a starting dose of $2000 \mathrm{mg} / \mathrm{kg}$ body weight. Animal were observed individually after dosing once during the first 30 min. periodically during the first $24 \mathrm{hr}$ with special attention given during first $4 \mathrm{~h}$. OECD guidelines, No. 423.

\subsubsection{Effect of AEAV on renal artery-occluded hypertensive rats (17).}

Male Wister rats were divided into the 6 groups each group consisting six animals. Animals in normal control and negative control groups received distilled water. Aqueous extract of A. Vasica was administered orally at the dose level of 100,200 and $400 \mathrm{mg} / \mathrm{kg}$ to the treatment groups for six week. At the end of the day treatment, animal were anesthetized by intraperitoneal injection of $1.25 \mathrm{gm} / \mathrm{kg}$ of urethane. A small incision was given on the left side of peritoneal cavity of the animal to expose left kidney. The renal artery was occluded for the $4 \mathrm{~h}$ by using renal bulldog clamp. The jugular vein was cannulated for the administration of test drug. The carotid artery was cannulated to measure the blood pressure and connected to the blood pressure transducer of power lab eight channel recorders. After stablisation blood pressure, the renal bulldog clamp was removed. this lead to rise in blood pressure as a consequence of elevated plasma rennin level. After bulldog clamp was removed the std. and test drug were administered immediately, $1 / 10^{\text {th }}$ of the oral administered dose of the $\mathrm{A}$. Vasica aqueous extract i.e. 10, 20 and $40 \mathrm{mg} / \mathrm{kg}$ was given respective group through jugular vein and parameter like BP, SBP, DBP and MABP were measured at different time intervals (10, 15,30,45,60 min.) all parameter for each animal were recorded in normal group without clamping renal artery. Captopril ( $1 \mathrm{mg} / \mathrm{kg}$, i.v. $)$ was used as a positive control. Changes in the parameter of treated groups were compared with negative control.

\section{Statistical Analysis}

The statistical significance was assessed using one way analysis of variance (ANOVA) followed by Dunnet comparison test. The values were expressed as mean \pm SEM and $\mathrm{p}<0.05$ was considered significant.

\subsection{Acute toxicity study}

\section{Result \& Discussions}

No mortality and no signs of toxicity were found after administration of a limit dose of $2000 \mathrm{mg} / \mathrm{kg}$ body weight of extract of Adhatoda Vasica leaves in acute toxicity test carried as per the OECD guidelines no. 423. The substance might be considered to have an LD50 value above $2000 \mathrm{mg} / \mathrm{kg}$ body weight. Hence for administration the doses selected were $100 \mathrm{mg} / \mathrm{kg}$ and $400 \mathrm{mg} / \mathrm{kg}$ and for intravenous administration the doses were 10,20 and $40 \mathrm{mg} / \mathrm{kg}$.

\subsection{Effect of AEAV on renal artery-occluded hypertensive rats.}




\subsubsection{Effect of AEAV on BP in retail artery-occluded hypertensive rats}

Removal of bulldog clip in ligated control group resulted in significant $(\mathrm{p}<0.05)$ increase in BP. pretreatment with AEAV 100,200 and $400 \mathrm{mg} / \mathrm{kg}$, p.o. for six weeks and 10,20, and $40 \mathrm{mg} / \mathrm{kg}$, i.v. on the day of experiment showed significant $(\mathrm{p}<0.05)$ decrease in BP in dose dependent manner at different time intervals when compared with ligated control group. In addition Captopril $(1 \mathrm{mg} / \mathrm{kg})$ produced significant $(\mathrm{p}<0.05)$ reduction in BP as compared to ligated control group.

\begin{tabular}{|c|c|c|c|c|c|c|}
\hline \multirow{3}{*}{$\begin{array}{l}\text { S. } \\
\text { No. }\end{array}$} & \multirow{3}{*}{$\begin{array}{c}\text { Treatment } \\
(\mathrm{Mg} / \mathrm{Kg})\end{array}$} & \multirow{3}{*}{ Stabilization } & \multicolumn{4}{|c|}{ BP(In mmHg) } \\
\hline & & & \multicolumn{4}{|c|}{ Post Treatment } \\
\hline & & & 15 Min & 30 Min & 45 Min & 60 Min \\
\hline 1 & Normal Control & $84.13 \pm 7.559$ & $84.07 \pm 8.851$ & $83.26 \pm 9.221$ & $83.40 \pm 8.429$ & $84.45 \pm 8.739$ \\
\hline 3 & Captopril (1) & $79.23 \pm 3.188$ & $64.21 \pm 5.339 *$ & $62.30 \pm 3.662 *$ & $60.88 \pm 2.491 *$ & $60.41 \pm 3.479 *$ \\
\hline 4 & AEAV 1 & $86.21 \pm 6.287$ & $84.66 \pm 5.915^{*}$ & $83.03 \pm 3.584 *$ & $80.01 \pm 3.876^{*}$ & $72.07 \pm 4.518^{*}$ \\
\hline 5 & AEAV 2 & $86.56 \pm 8.026$ & $84.95 \pm 7.629 *$ & $80.41 \pm 8.306^{*}$ & $72.79 \pm 12.132 *$ & $71.10 \pm 9.364 *$ \\
\hline
\end{tabular}

Table: 1 Effect of AEAV on BP in retail artery-occluded hypertensive rats

Values are expressed as mean \pm SEM, $(n=6),{ }^{\circledR} \mathrm{p}<0.05$ as compared with Normal control, * $\mathrm{p}<0.05$ as compared with Ligated control. Data analyzed by one way ANOVA followed by Dunnet test. Stabilization of BP before the treatments for $10 \mathrm{~min}$; AEAV 1, AEAV 2 \& AEAV 4: AEAV 100, $200 \& 400 \mathrm{mg} / \mathrm{Kg}$. p.o. for six week and 10, 20 and 40, $\mathrm{mg} / \mathrm{Kg}$, i.v. on the day of experiment respectively.

\subsubsection{Effect of AEAV on SBP in renal artery-occluded hypertensive rats}

Removal of bulldog clip in ligated control group resulted in significant $(p<0.05)$ increase in SBP. pretreatment of animal with AEAV 100, 200 and $400 \mathrm{mg} / \mathrm{kg}$ p.o. for six week and 10,20, and $40 \mathrm{mg} / \mathrm{kg}$ i.v. on the day of experiment showed significant $(\mathrm{p}<0.05)$ decrease in SBP in dose dependent manner at different time intervals, when compared with ligated control group . in addition, Captopril ( $1 \mathrm{mg} / \mathrm{kg}$ i.v.) produced significant $(\mathrm{p}<0.05)$ reduction in SBP as compared to ligated control group.

\begin{tabular}{|c|c|c|c|c|c|c|}
\hline \multirow{3}{*}{ S. No. } & \multirow{3}{*}{$\begin{array}{c}\text { Treatment } \\
\text { (Mg/Kg) }\end{array}$} & \multirow{3}{*}{ Stabilization } & \multicolumn{4}{|c|}{ SBP(In mmHg) } \\
\hline & & & \multicolumn{4}{|c|}{ Post Treatment } \\
\hline & & & 15 Min & 30 Min & 45 Min & 60 Min \\
\hline 1 & Normal Control & $92.16 \pm 5.563$ & $89.96 \pm 7.196$ & $90.09 \pm 7.654$ & $90.09 \pm 87.497$ & $92.79 \pm 8.011$ \\
\hline 2 & Ligated Control & $97.91 \pm 2.846$ & 119.64+2.349@ & 111.74土2.431@ & 109.20土3.461@ & 108.77士2.550@ \\
\hline 3 & Captopril (1) & $91.12 \pm 2.868$ & $77.53 \pm 1 . .803 *$ & $74.913 \pm 4.075^{*}$ & $73.26 \pm 4.744 *$ & $69.32 \pm 1.914 *$ \\
\hline 4 & AEAV 1 & $89.28 \pm 5.567$ & $88.83 \pm 4.175^{*}$ & $84.25 \pm 4.582 *$ & $80.14 \pm 4.285^{*}$ & $80.74 \pm 3.419 *$ \\
\hline 5 & AEAV 2 & $94.39 \pm 7.768$ & $87.70 \pm 5.854 *$ & $83.92 \pm 6.034 *$ & $76.96 \pm 7.740^{*}$ & $72.74 \pm 9.883^{*}$ \\
\hline 6 & AEAV 4 & $90.08 \pm 4.343$ & $84.49 \pm 4.038$ & $80.80 \pm 3.676^{*}$ & $76.22 \pm 1.595^{*}$ & $71.52 \pm 2.890 *$ \\
\hline
\end{tabular}

Table: 2 Effect of AEAV on SBP in retail artery-occluded hypertensive rats

Values are expressed as mean \pm SEM, $(n=6),{ }^{@} \mathrm{p}<0.05$ as compared with Normal control, $* \mathrm{p}<0.05$ as compared with Ligated control. Data analyzed by one way ANOVA followed by Dunnet test. Stabilization of SBP before the treatments for $10 \mathrm{~min}$; AEAV 1, AEAV 2 \& AEAV 4: AEAV 100, $200 \& 400 \mathrm{mg} / \mathrm{Kg}$. p.o. for six week and 10, 20 and 40, $\mathrm{mg} / \mathrm{Kg}$, i.v. on the day of experiment respectively.

\subsubsection{Effect of AEAV on DBP in renal artery-occluded hypertensive rats}

Removal of bulldog clip in ligated control group resulted in significant $(\mathrm{p}<0.05)$ increase in DBP. pretreatment of animal with AEAV 100, 200 and $400 \mathrm{mg} / \mathrm{kg}$ p.o. for six week and 10,20, and $40 \mathrm{mg} / \mathrm{kg}$ i.v. on the day of experiment showed significant $(\mathrm{p}<0.05)$ decrease in DBP in dose dependent manner at different time intervals, when compared with ligated control group . in addition, captopril $(1 \mathrm{mg} / \mathrm{kg}$ i.v.) produced significant $(\mathrm{p}<0.05)$ reduction in DBP as compared to ligated control group.

\begin{tabular}{|c|c|c|c|c|c|c|}
\hline \multirow{3}{*}{$\begin{array}{l}\text { S. } \\
\text { No. }\end{array}$} & \multirow{3}{*}{$\begin{array}{c}\text { Treatment } \\
(\mathrm{Mg} / \mathrm{Kg})\end{array}$} & \multirow{3}{*}{ Stabilization } & \multicolumn{4}{|c|}{ DBP(In mmHg) } \\
\hline & & & \multicolumn{4}{|c|}{ Post Treatment } \\
\hline & & & 15 Min & 30 Min & 45 Min & 60 Min \\
\hline 1 & Normal Control & $73.39 \pm 8.582$ & $76.25 \pm 10.998$ & $71.40 \pm 10.135$ & $69.05 \pm 8.845$ & $68.91 \pm 9.233$ \\
\hline 2 & Ligated Control & $79.37 \pm 6.436$ & 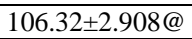 & 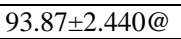 & 89.23土3.779@ & $85.41 \pm 4.099 @$ \\
\hline 3 & Captopril (1) & $68.99 \pm 4.239$ & $47.66 \pm 4.446^{*}$ & $47.26 \pm 2.536^{*}$ & $53.12 \pm 2.491 *$ & $47.95 \pm 2.199 *$ \\
\hline 4 & AEAV 1 & $79.16 \pm 6.633$ & $70.25 \pm 5.696^{*}$ & $68.74 \pm 6.173^{*}$ & $62.40 \pm 5.885^{*}$ & $62.86 \pm 3.703^{*}$ \\
\hline 5 & AEAV 2 & $75.39 \pm 7.480$ & $71.49 \pm 6.132 *$ & $66.18 \pm 3.819^{*}$ & $59.61 \pm 8.971^{*}$ & $57.57 \pm 8.340^{*}$ \\
\hline 6 & AEAV 4 & $71.83 \pm 4.921$ & $71.05 \pm 5.880^{*}$ & $63.40 \pm 3.471^{*}$ & $58.43 \pm 3.124 *$ & $56.86 \pm 2.253^{*}$ \\
\hline
\end{tabular}

Table: 3 Effect of AEAV on DBP in retail artery-occluded hypertensive rats

Values are expressed as mean \pm SEM, $(n=6),{ }^{@} \mathrm{p}<0.05$ as compared with Normal control, $* \mathrm{p}<0.05$ as compared with Ligated control. Data analyzed by one way ANOVA followed by Dunnet test. Stabilization of 
Antihypertensive activity of aqueous extract of Adhatoda Vasica in hypertensive rats.

DBP before the treatments for $10 \mathrm{~min}$; AEAV 1, AEAV 2 \& AEAV 4: AEAV 100, 200 \& 400 mg/Kg. p.o. for six week and 10, 20 and 40, $\mathrm{mg} / \mathrm{Kg}$, i.v. on the day of experiment respectively.

\subsubsection{Effect of AEAV on MABP in renal artery-occluded hypertensive rats}

Removal of bulldog clip in ligated control group resulted in significant $(p<0.05)$ increase in MABP. pretreatment of animal with AEAV 100, 200 and $400 \mathrm{mg} / \mathrm{kg}$ p.o. for six week and 10,20, and $40 \mathrm{mg} / \mathrm{kg}$ i.v. on the day of experiment showed significant $(\mathrm{p}<0.05)$ decrease in MABP in dose dependent manner at different time intervals, when compared with ligated control group . in addition , captopril ( $1 \mathrm{mg} / \mathrm{kg}$ i.v.) produced significant $(\mathrm{p}<0.05)$ reduction in MABP as compared to ligated control group.

\begin{tabular}{|c|c|c|c|c|c|c|}
\hline \multirow{2}{*}{$\begin{array}{c}\text { S. } \\
\text { No. }\end{array}$} & Treatment (Mg/Kg) & \multirow{2}{*}{$\begin{array}{c}\text { Stabilizatio } \\
n\end{array}$} & $\mathbf{n}$ & \multicolumn{4}{|c|}{ MABP(In mmHg) } \\
\cline { 4 - 6 } & & & $\mathbf{1 5}$ Min & $\mathbf{3 0}$ Min & $\mathbf{4 5}$ Min & $\mathbf{6 0}$ Min \\
\hline 1 & Normal Control & $83.09 \pm 8.109$ & $81.93 \pm 9.326$ & $81.19 \pm 9.696$ & $80.62 \pm 8.620$ & $77.99 \pm 9.156$ \\
\hline 2 & Ligated Control & $86.33 \pm 5.116$ & $115.26 \pm 3.911 @$ & $108.73 \pm 3.799 @$ & $105.68 \pm 2.801 @$ & $101.81 \pm 4.457 @$ \\
\hline 3 & Captopril (1) & $75.43 \pm 3.450$ & $59.41 \pm 5.101^{*}$ & $59.11 \pm 2.163^{*}$ & $57.44 \pm 2.053^{*}$ & $54.63 \pm 3.625^{*}$ \\
\hline 4 & AEAV 1 & $79.97 \pm 6.547$ & $76.23 \pm 4.333^{*}$ & $75.86 \pm 4.657^{*}$ & $73.84 \pm 4.296^{*}$ & $69.26 \pm 4.514^{*}$ \\
\hline 5 & AEAV 2 & $83.77 \pm 8.815$ & $74.17 \pm 4.689^{*}$ & $72.96 \pm 5.034^{*}$ & $70.42 \pm 4.921^{*}$ & $67.34 \pm 4.664^{*}$ \\
\hline 6 & AEAV 4 & $79.03 \pm 4.611$ & $73.59 \pm 4.084^{*}$ & $70.25 \pm 5.568^{*}$ & $68.08 \pm 5.650^{*}$ & $68.30 \pm 6.031^{*}$ \\
\hline
\end{tabular}

Table: 4 Effect of AEAV on MABP in retail artery-occluded hypertensive rats.

Values are expressed as mean \pm SEM, $(n=6),{ }^{\circledR} \mathrm{p}<0.05$ as compared with Normal control, $* \mathrm{p}<0.05$ as compared with Ligated control. Data analyzed by one way ANOVA followed by Dunnet test. Stabilization of MABP before the treatments for $10 \mathrm{~min}$; AEAV 1, AEAV 2 \& AEAV 4: AEAV 100, 200 \& 400 mg/Kg. p.o. for six week and 10, 20 and 40, $\mathrm{mg} / \mathrm{Kg}$, i.v. on the day of experiment respectively.

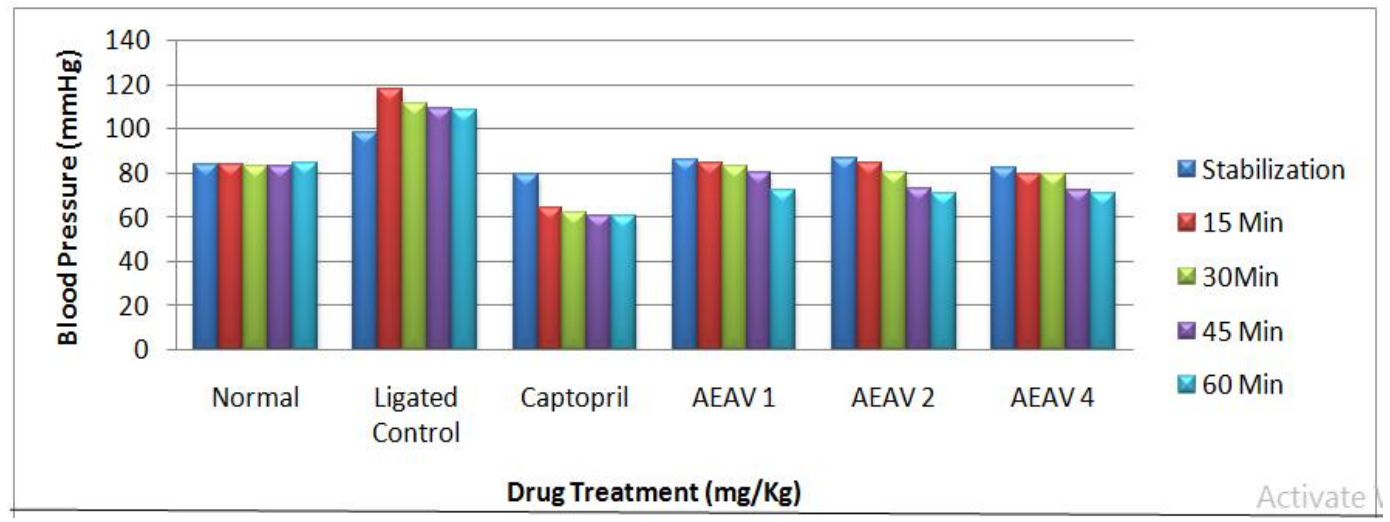

Figure: 1 Effect of AEAV on BP in Renal artery - occluded hypertensive rats

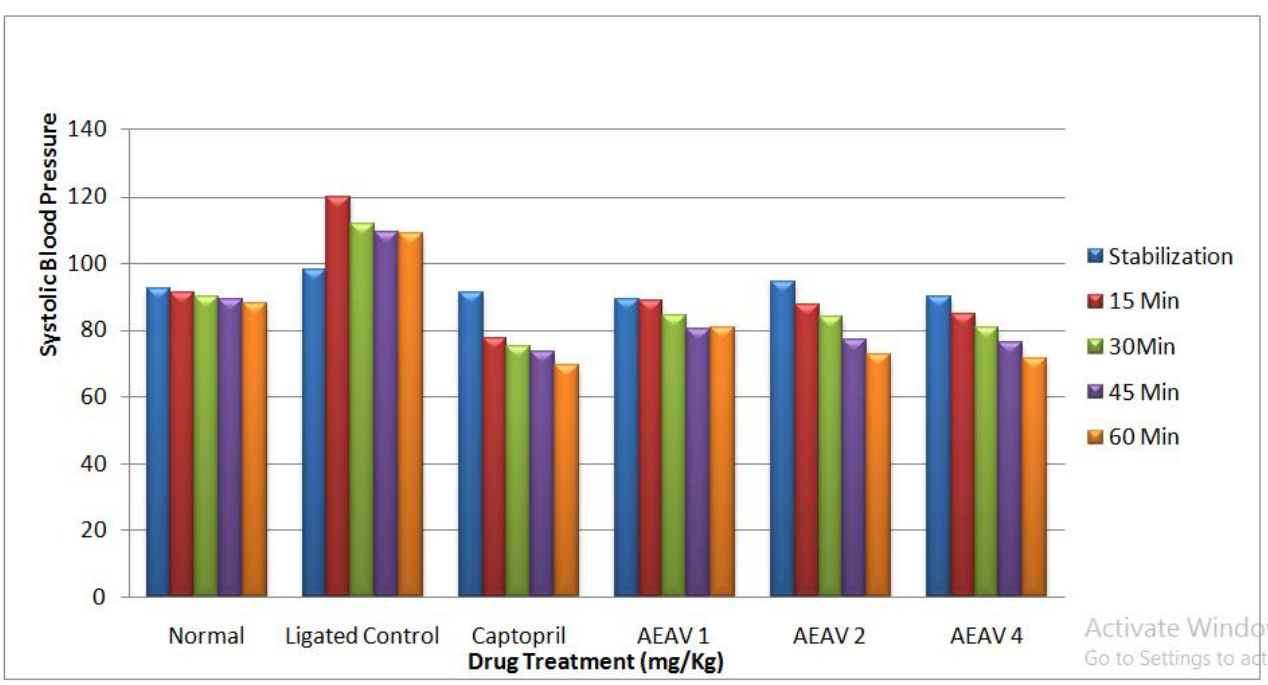

Figure: 2 Effect of AEAV on SBP in Renal artery - occluded hypertensive rats 


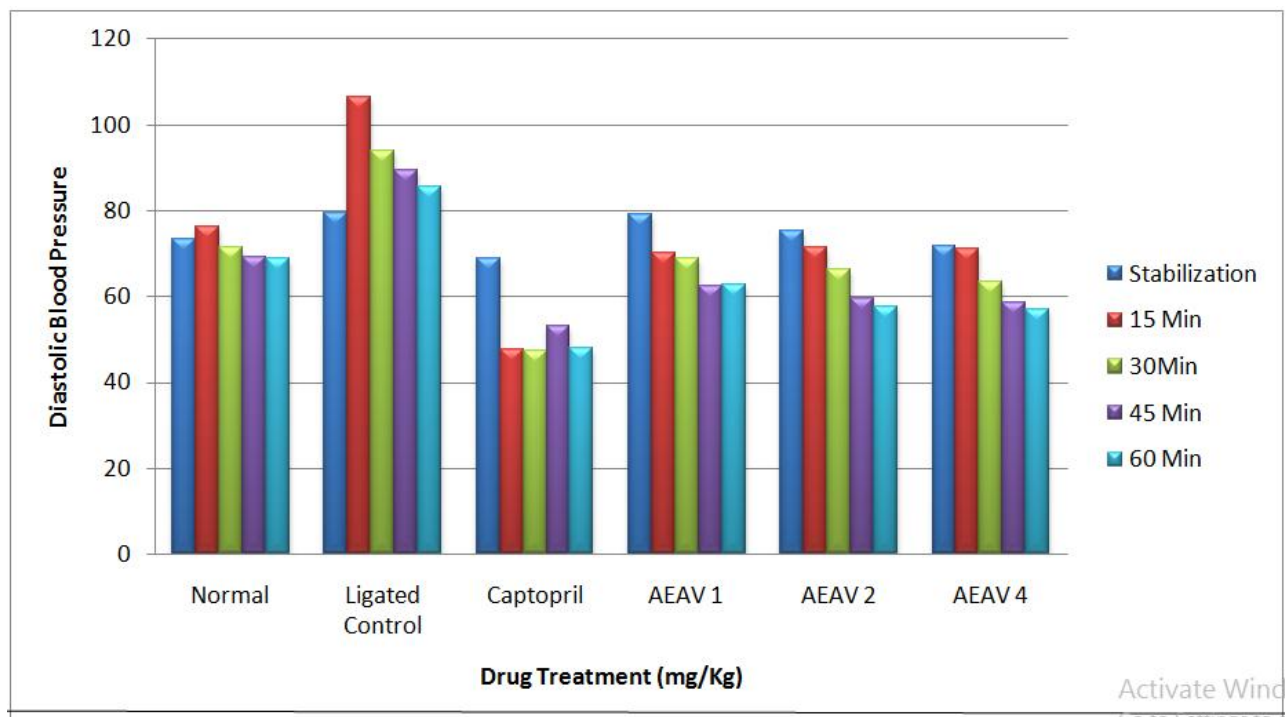

Figure: 3 Effect of AEAV on DBP in Renal artery - occluded hypertensive rats

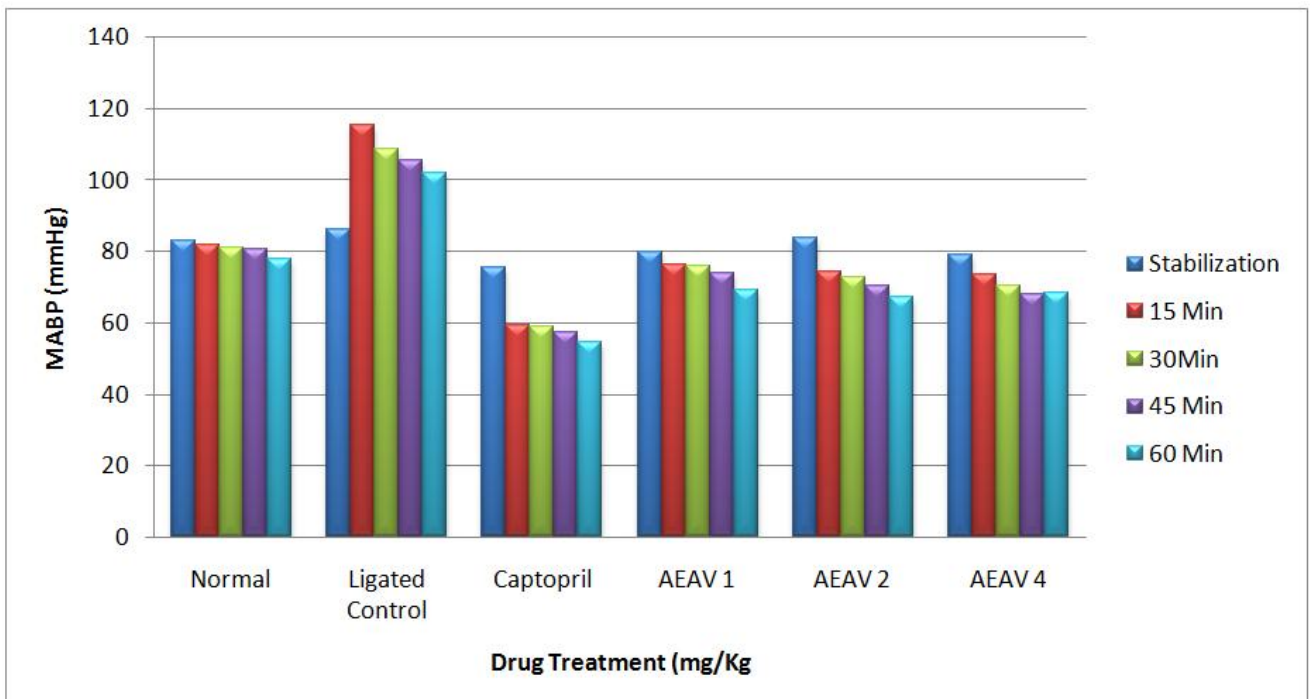

\section{Conclusion}

Hypertension is major risk factor for stroke, myocardial infaraction, and heart and kidney failure. Worldwide hypertension is estimated to cause 7.1 million premature deaths and $4.5 \%$ of the disease burden. Treating hypertension has been associated with about a $40 \%$ reduction in the risk of stroke and about a $15 \%$ reduction in the of myocardial infaraction. In consequence, current clinical practice guidelines identify lowering blood pressure as a priority in the treatment of people with hypertension (magos et al., 2008). The result of present study showed that the AEAV extract had produced significant reduction in BP, SBP, DBP, and MABP at different time interval in dose dependant manner. From the result of present study and mechanism involve in the induction of hypertension in goldblatt model, it was revealed that antihypertensive effect observed for AEAV may possibly be due to decrease in rennin release and angiotensin II levels; AT 1 \& AT2 receptors antagonism; inhibition of aldosterone secretion; increase prostaglandin synthesis or inhibition of ACE that is involve in synthesis of angiotensin II from angiotensin I.

\section{Reference}

[1] Norman, k., shanthi, M., neal, p., Judith w. 2003. World health organization (WHO) /international society of hypertension (ISH) statement on management of hypertension, journal of hypertension, 21:1983-1992.

[2] Sharma H.L., Sharma K.K.. Principal of pharmacology, First edition, Paras medical publishing, Hyderabad, India, 2007; Page No. 227-296.

[3] Kalia A. N., Text Book of industrial pharmacognosy. New delhi India; Oscar Publication, 2005; pp 3-

[4] Kirtikar K. R. and Basu B. D., Indian Medicinal plants, text vol -III, International book distributors book sellers and publishers, Dehradun, India 2005: pp 1899-1902.

[5] Pundarikakshudu K., Kalantari H., Gotwandi G.C, Effect of Gibberlic acid on quinazoline alkaloid of Adhatoda Vasica nees. Indian drugs 23(12), 1986; Page No. 652-653. 
[6] Yadav A. K., Tangpu V., Anticestodal activity of Adhatoda Vasica extract against Hymenolepsis dimuinuta infection in rats. J Ethnopharmacol 119(2), 2008: pp 322-4.

[7] Shrivastava N., Shrivastava A., Banerjee A., Nivsarkar M., Antiulcer activity of Adhatoda Vasica Nees, J herb Pharmacother, 6(2), 2006; pp 43-9.

[8] Dhuley J. N., Antitussive effect of Adhatoda Vasica extract on mechanical and chemical stimulation induced coughing in animals, J Ethnopharmacol, 67(3), 1991; pp 361-365.

[9] Grange J.M., Shell N.J., Activity of bromohexine and ambroxol, semisynthetic derivatives of vasicine from the Indian shrub Adhatoda Vasica against mycobacterium tuberculosis in vitro, J Ethanopharmacol, 50(1), 1996; pp 49-53.

[10] Bhattacharyya D., Pandit S.,Jana U., Sen S. and Sur T. K., Hepatoprotective activity of adatoda Vasica aqueous leaf extract on Dgalactosamine - induced liver damage in rats, Fitoterpia, 76(2), 2005; pp 223-225.

[11] Kumar A., Ram J., Samarth R. M., Kumar M., Modulatory influence of Adhatoda Vasica nees leaf extract against gamma irradiation in swiss albino mice, Phytomedicine, 12(4), 2005; pp 285-293.

[12] Chakraborty A., Brantner A. H., Study of alkaloids from Adhatoda Vasica novel abortificient, Indian drugs, 24(9), 1986; pp 425429 .

[13] D’Cruz J.L., Nimbkar A. Y., Kokate C. K., Evalution of Fruits of Piper Longum Linn and Leaves of Adhatoda Vasica nees for anthelmintic activity, Indian drugs 1980; pp 98-101.

[14] Gao H., Huang Y. N., Gao B., Kawabata J., Inhibitory effect on a glucosidase by Adatoda Vasica Nees, Food Chemistry, 108, 2008; pp 965-972.

[15] Talib M., Gulfarz M., Mussaddeq Y., Effect of crude extract of Adhatoda Vasica nees on diabetic patients, Online Journal of biological Sciences 2(7), 2002, pp 436-437.

[16] Ofem O. E., Eno A.E., Imoru J., Nkanu E., Effect of crude aqueous leaf extract of Viscum album in hypertensive rats, Indian journal of Pharmacology 2, Vol 39(1),2007; pp 15-19.

[17] Vogel H.G., Vogel W.H., Scholkens B.A., Sandow J., Muller G., Drug discovery and evaluation pharmacological assays, II edition, springer publication germany 2002; pp 323-326.

IOSR Journal of Pharmacy and Biological Sciences (IOSR-JPBS) is UGC approved Journal with Sl. No. 5012, Journal no. 49063.

Satkar Prasad. "Antihypertensive Activity of Aqueous Extract of Adhatoda Vasica in Hypertensive Rats." IOSR Journal of Pharmacy and Biological Sciences (IOSR-JPBS) 12.4 (2017): 63-68. 